\title{
HOÀN THIỆN KHUNG PHÁP LÝ VỀ THI TRƯỜNG PHÁI SINH TIỀN TỆ TẠI CÁC NGÂN HÀNG THƯƠNG MẠI VIẸT NAM
}

\author{
COMPLETE THE LEGAL FRAMEWORK FOR THE DERIVATIVE \\ CURRENCY MARKET AT VIETNAMESE COMMERCIAL BANKS
}

Ngày nhận bài: 25/02/2019 Ngày chấp nhận đăng: 02/04/2019 Ngày đăng: 05/6/2019

\section{Trần Quốc Thịnh ${ }^{1}$}

\section{Tóm tắt}

Trong xu hướng hội nhập, Việt Nam là một quốc gia đang phát triển rất cần huy động nguồn lực vốn cho tăng trưởng kinh tế thông qua thị trường tài chính. Do vậy việc hoàn thiện khung pháp lý tạo nền tảng cho thị trường tiền tệ phái sinh (TTTTPS) là vấn đề đáng quan tâm. Bài viết trên cơ sở khảo sát 109 chuyên gia là những nhà lãnh đạo các ngân hàng thương mại (NHTM) để nhìn nhận thực trạng áp dụng khung pháp lý TTTTPS tại Việt Nam. Kết quả cho thấy khung pháp lý hiện hành tương đối hoàn chỉnh nhưng vẫn còn một số vấn đề bất cập. Từ đó, bài viết đề xuất một số kiến nghị, theo đó cơ quan nhà nước như Quốc hội, Chính phủ, Ngân hàng Nhà nước cần sớm sửa đổi, bổ sung một số Luật, Pháp lệnh, Nghị định và Thông tư liên quan nhằm tạo sự thống nhất trong khung pháp lý liên quan TTTTPS. Theo đó khung pháp lý phù hợp với thông lệ quốc tế, đảm bảo tính thống nhất và kịp thời, hoàn thiện hệ thống thanh toán, giao dịch, kinh doanh, liên quan đến phái sinh về lãi suất và ngoại hối. Đây là cơ sở góp phần lành mạnh hóa môi trường pháp lý cho TTTTPS Việt Nam phát triển đáp ứng xu thế hội nhập quốc tế.

Tù khóa: Tiền tệ phái sinh, khung pháp lý, thị trường tiền tệ.

\begin{abstract}
In the integration trend, a developing country in Vietnam needs to mobilize capital resources for economic growth through the financial market. Therefore, completing the legal framework to create the foundation for the derivative currency market (TTTTPS) is of concern. The article is based on a survey of 109 experts who are leaders of Vietnamese commercial banks to recognize the status of apply in the legal framework of the derivative currency market in Vietnam. The results show that the current legal framework is relatively complete but there are still some shortcomings. Since then, the article proposes a number of recommendations, according to which state agencies such as the National Assembly, the Government and the State Bank should soon amend and supplement a number of relevant Laws, Ordinances, Decrees and Circulars to create consistency in the legal framework related to TTTTPS. Accordingly, the legal framework is consistent with international practices, ensuring consistency and timeliness, perfecting the payment, transaction and business system, relating to derivatives of interest rates and foreign exchange. This is the basis to contribute to the healthy legal environment for Vietnam TTTTPS to meet the trend of international integration. Keywords: Derivative currency, legal framework, currency market.
\end{abstract}

\footnotetext{
${ }^{1}$ Trường Đại học Ngân hàng TP.HCM, Email: thinhtq@buh.edu.vn
} 


\section{1. Đặt vấn đề}

Trong xu hướng toàn cầu hóa, việc phát triển thị trường vốn có ý nghĩa quan trọng đối với các quốc gia nhằm thu hút nguồn lực tài chính cho phát triển kinh tế. Sự phát triển của thị trường tài chính, trong đó tài chính phái sinh đóng vai trò thiết yếu cho phát triển thị trường vốn nên các quốc gia luôn quan tâm đến vấn đề này, đặc biệt là khung pháp lý làm nền tảng cho sự ổn định và bền vững (Chance và Brooks, 2016). Các nghiên cứu điển hình Amato và Gyntelberg (2005); Carlson và cộng sự (2006); Chiu (2010); Biggins và Scott (2013) đã tập trung đánh giá từng công cụ phái sinh (CCPS) liên quan đến ngoại hối, lãi suất. Trong xu hướng hội nhập và phát triển với khu vực và quốc tế, Việt Nam đã có nhiều cải tiến trong các văn bản pháp luật để hoàn thiện khung pháp lý, tuy nhiên vẫn còn một số tồn tại nhất định liên quan đến sự phù hợp theo thông lệ quốc tế như Nguyễn Thị Loan (2013) hay Nguyễn Thị Nhung và Trần Thị Minh Tuyền (2014), hay các quy định chưa đáp ứng nhu cầu thực tiễn như Nguyễn Thị Lan (2017) và Trần Thị Khám Trâm, Nguyễn Hồ Thị Phương Thảo và Vũ Thị Kim Nhung (2018). Điều này đặt ra những thách thức cho quá trình phát triển của thị trường này trong bối cảnh hội nhập quốc tế.

\section{Cơ sở lý thuyết thị trường phái sinh tiền tệ}

2.1. Lược sử quá trình hình thành và phát triển

Thị trường tiền tệ quốc tế được thành lập bởi Sàn giao dịch Chicago vào năm 1972 để giao dịch tương lai bằng ngoại tệ. Sau đó, một số sàn giao dịch khác trên thế giới đã thực hiện giao dịch hợp đồng tương lai, trong số này có Sàn giao dịch tương lai New York, Sàn giao dịch tương lai tài chính quốc tế London, Sàn giao dịch tương lai Toronto và Sàn giao dịch tiền tệ quốc tế Singapore. Trong những năm 1980, các thị trường được phát triển cho các quyền chọn về ngoại hối, các quyền chọn về chỉ số chứng khoán và các quyền chọn về hợp đồng tương lai. Sở giao dịch chứng khoán Philippines là sàn giao dịch đầu tiên để giao dịch quyền chọn ngoại hối. Đầu những năm 1970, thị trường tương lai tài chính đầu tiên là Thị trường tiền tệ quốc tế (International Monetary Market - IMM) được thành lập vào năm 1972, và sau đó năm 1982 Sàn giao dịch tài chính tương lai quốc tế London (London International Financial Futures Exchange - LIFFE) được thành lập (Tiwari và Turan, 2004). Ngày nay, TTTTPS đã được triển khai áp dụng ở hầu hết các quốc gia trên thế giới với tốc độ tăng trưởng nhanh. Trong báo cáo Quý 3 năm 2019, Ngân hàng Thanh toán Quốc tế (BIS) nhìn nhận, TTTTPS trên thị trường thế giới trong thời gian qua có tốc độ tăng trưởng nhanh, và nếu so sánh 2 năm gần đây thì năm 2018 đã tăng 18,22\%, điển hình phái sinh lãi suất tăng 18,09\%, ngoại hối tăng $24,81 \%$; và xét riêng trên thị trường châu Á Thái Bình Dương, thị trường TTTTPS tăng 9,35\%, trong đó phái sinh lãi suất tăng 6,44\%, ngoại hối tăng 41,67\% (BIS, 2019).

\subsection{Khái niệm}

Khung hay khuôn khổ là hệ thống những quy định và tiêu chuẩn được thiết lập cho hoạt động nhất định và khung pháp lý là hệ thống các văn bản pháp luật từ lập pháp, hành pháp và tư pháp (Chance và Brooks, 2016). Phái sinh tiền tệ (Monetary derivative) là hợp đồng có giá trị giữa hai hoặc nhiều bên dựa trên tài sản tài chính cơ bản đã được thỏa thuận bắt nguồn từ ngoại tệ, lãi suất (IFRS Foundation, 2019). Do đó, TTTTPS (Derivative currency market) được hiểu là nơi trao đổi, mua bán các hợp đồng giữa các bên trên cơ sở các công cụ tài chính. Thị trường này có thể được phân thành thị trường niêm yết (Exchange -traded) và thị trường phi tập trung (Over the counter - OTC), và tương ứng tính pháp lý cũng 
sẽ khác nhau trong mỗi phân khúc của thị trường (Chance và Brooks, 2016).

\subsection{Nhũng nghiên cứu trước liên quan}

Các nghiên cứu liên quan đến TTTTPS được một số nhà nghiên cứu quan tâm cả trong và ngoài nước. Có thể nhận thấy TTTTPS là phức tạp nên việc hình thành và hoàn thiện khung pháp lý là một trong những vấn đề nền tảng để thực thi đối với thị trường này. Đối với các nghiên cứu nước ngoài, một số nghiên cứu chuyên sâu trong từng công cụ phái sinh liên quan đến ngoại hối, lãi suất như Amato và Carlson và cộng sự (2006) và Chiu (2010). Về phái sinh lãi suất, Carlson và cộng sự (2006) đã phân tích các quy định liên quan đến phái sinh lãi suất của thị trường. Theo tác giả về quy định, ngân hàng đồng ý thanh toán cho đối tác dựa trên tỷ giá thả nổi để nhận thanh toán lãi suất cố định. Tuy nhiên, trong thực tế các quy định ràng buộc đã ảnh hưởng đến sự phát triển của hình thức này. Tác giả đã đề xuất cần có những linh hoạt hơn để người tham gia và các ngân hàng sẽ giảm thiểu những rủi ro về lãi suất. Đối với phái sinh ngoại hối, Chiu (2010) xem xét hợp đồng hoán đổi tỷ giá của một số quốc gia thuộc châu Âu, châu Á và khu vực Bắc Mỹ, trong giai đoạn 1990 - 2008. Tác giả tập trung phân tích hoán đổi tiền tệ chéo để phòng ngừa rủi ro lãi suất của các doanh nghiệp và nhìn nhận công cụ này hữu ích cho người sử dụng. Tuy nhiên, rào cản hiện nay là các quy định giữa các quốc gia hay khu vực chưa đảm bảo tính thống nhất nên cản trở trong giao dịch. Tác giả đã đề xuất cần vận dụng khung pháp lý chung nhất theo chuẩn quốc tế để thuận lợi cho người tham gia trên thị trường tiền tệ quốc tế.

Tại Việt Nam, các nghiên cứu liên quan đến TTTTPS khá phổ biến, tuy nhiên các nghiên cứu tập trung vào quy định pháp lý thì còn khiêm tốn. Đối với phái sinh ngoại hối, một số nghiên cứu tập trung vào phái sinh ngoại hối như Nguyễn Thúy (2008); Nguyễn Thị Loan (2013); Nguyễn Thị Lan (2017); Trần Thị Khám Trâm, Nguyễn Hồ Thị Phương Thảo và Vũ Thị Kim Nhung (2018). Đối với Nguyễn Thúy (2008) nghiên cứu sự phát triển phái sinh ngoại hối trên thị trường Việt Nam, giai đoạn 2003 - 2007. Tác giả đã phân tích thực trạng hoạt động phái sinh ngoại hối của Việt Nam và nhìn nhận thị trường này tiềm ẩn nhiều rủi ro do hệ thống chính sách pháp luật chưa hoàn thiện cả về mặt văn bản pháp luật và tính khả thi của các quy định trong thực tiễn. Tác giả đã đề xuất giải pháp cần hoàn chỉnh hệ thống văn bản pháp lý để tạo sự thống nhất trong giao dịch nhằm đảm bảo sự tin cậy cho người tham gia trên thị trường. Nguyễn Thị Loan (2013) đã phân tích thực trạng phát triển công cụ tài chính phái sinh tiền tệ tại các NHTMT Việt Nam trong giai đoạn 2007 - 2011. Tác giả nhìn nhận một số nguyên nhân và hạn chế ảnh hưởng đến sự phát triển các công cụ này tại NHTM Việt Nam, trong đó xuất phát từ quy định chưa chặt chẽ trong các giao dịch mua bán ngoại tệ, cũng như các quy định liên quan đến hoạt động kinh doanh tiền tệ chưa tương thích với biến động của thị trường. Từ đó, tác giả đã đề xuất một số biện pháp như Ngân hàng Nhà nước (NHNN) cần nghiên cứu, sửa đổi các quy định liên quan đến kinh doanh tiền tệ theo xu hướng hội nhập quốc tế phù hợp điều kiện môi trường Việt Nam. Đồng thời, Bộ Tài chính cần nghiên cứu ban hành quy định về kế toán thuế liên quan đến công cụ này đối với doanh nghiệp. Nguyễn Thị Lan (2017) đã xem xét điều tiết thị trường ngoại tệ của NHNN trong những năm 2012 - 2017. Tác giả đã phân tích vai trò điều tiết thị trường ngoại tệ của NHNN và nhìn nhận các giao dịch ngoại hối đã hình thành ở Việt Nam nhưng chưa phù hợp với những quy định thông lệ quốc tế. Do đó theo tác giả, NHNN cần tiếp tục hoàn hiện khuôn khổ pháp lý cho các CCPS ngoại hối để tạo ra một môi trường pháp lý phù hợp với các quy 
định quốc tế. Trần Thị Khám Trâm, Nguyễn Hồ Thị Phương Thảo và Vũ Thị Kim Nhung (2018) đã nghiên cứu thực trạng phát triển sản phẩm phái sinh ngoại hối tại các NHTM ở thành phố Huế. Nhóm tác giả đã phân tích giai đoạn 2014 - 2017 để xem xét những bất cập trong thực tế triển khai phái sinh ngoại hối tại các ngân hàng này. Qua đó, tác giả đã nhìn nhận các quy định liên quan đến sản phẩm này còn xa lạ với khách hàng, cũng như trong nhận thức còn khác biệt giữa NHTM và khách hàng. Thậm chí bản thân NHTM chưa thật sự quan tâm trong triển khai bởi sự phức tạp trong các quy định về phái sinh ngoại hối. Riêng nghiên cứu về phái sinh lãi suất có nghiên cứu của Nguyễn Thị Nhung và Trần Thị Minh Tuyền (2014). Theo tác giả mức độ áp dụng các CCPS ở Việt Nam còn hạn chế do những quy định phức tạp làm cản trở đối với quá trình phát triển các công cụ này và thật sự chưa được xem như công cụ trong việc phòng ngừa rủi ro. Từ đó, tác giả đã đề xuất các quy định cần rõ ràng cũng như các hướng dẫn thực thi phù hợp để tạo điều kiện cho các doanh nghiệp tham gia trên thị trường.

Từ các nghiên cứu trước có thể nhìn nhận, ở các nghiên cứu nước ngoài, tập trung trong các quy định có những chủ đề liên quan về TTTTPS nhưng chưa có nghiên cứu cho riêng Việt Nam. Đối với các nghiên cứu tại Việt Nam, các nghiên cứu liên quan đến quy định pháp lý đã được quan tâm nhưng ở giai đoạn trước đây, trong khi gần đây trong xu hướng hội nhập quốc tế, Việt Nam đã ban hành mới, sửa đổi, bổ sung một số Luật, Nghị định, Thông tư liên quan thì chưa có nghiên cứu tập trung về khung pháp lý cho thị trường này.

\section{Thiết kế nghiên cứu}

Bài viết sử dụng phương pháp nghiên cứu định tính chủ yếu là phân tích, tổng hợp để phù hợp với mục tiêu và nội dung nghiên cứu, và phỏng vấn và thảo luận các chuyên gia.

\subsection{Quy trình nghiên cứu}

Từ mục tiêu chính của nội dung nghiên cứu, đề tài thực hiện quy trình cụ thể như xác định hệ thống cơ sở lý thuyết về khung pháp lý TTTTPS; xây dựng bảng hỏi sơ thảo bao gồm hai nội dung về hệ thống văn bản pháp luật và việc áp dụng các quy định trong thực tiễn liên quan đến các vấn đề về TTTTPS; thảo luận với các chuyên gia là những người có kiến thức chuyên sâu về lý luận và thực tiễn để có nhìn nhận chuyên sâu và xác đáng về bảng hỏi; hoàn chỉnh bảng hỏi trên cơ sở góp ý của các chuyên gia liên quan đến TTTTPS; tổng hợp dữ liệu của các bảng câu hỏi được xử lý bằng công cụ Excel thông qua khảo sát những đối tượng có liên quan và đây là dữ liệu sơ cấp; và trên cơ sở đó, đề tài sẽ có kết quả nghiên cứu đảm bảo phù hợp với mục tiêu nghiên cứu.

\subsection{Phuơng pháp chọn mẫu}

Các đối tượng khảo sát được chọn lọc gồm 109 chuyên gia, những lãnh đạo đang làm thực tế có kinh nghiệm và am tường trong lĩnh vực tài chính ngân hàng để nhìn nhận vấn đề được xác thực, trong đó gồm 42 chuyên gia là Ban giám đốc và 67 chuyên gia là trưởng, phó phòng pháp chế, ngoại hối, kinh doanh tiền tệ... của một số NHTM tại TP.HCM. Các đối tượng được khảo sát trong thời gian từ tháng 9 năm 2018 đến tháng 2 năm 2019. Do mẫu có chọn lọc được sử dụng trong phương pháp nghiên cứu định tính nên số lượng mẫu này đảm bảo mức độ tin cậy của thông tin.

\subsection{Thiết kế nội dung bảng hỏi}

Đối với bảng câu hỏi liên quan hệ thống nội dung khung pháp lý thuộc TTTTPS có thể nhìn nhận trên cơ sở về nội dung quy định trong các văn bản pháp luật và thực tiễn áp dụng TTPS. Các văn bản pháp luật có liên quan gồm:

- Nhóm văn bản pháp luật chung có liên quan như Pháp lệnh Ngoại hối được Quốc hội 
ban hành năm 2005 và được sửa đổi, bổ sung năm 2013 là văn bản pháp lý cao nhất điều chỉnh các sản phẩm phái sinh ngoại tệ (viết tắt Pháp lệnh Ngoại hối) (UBTVQH, 2005; 2013). Bên cạnh đó, Nghị định số 70/2014/NĐ-CP quy định chi tiết thi hành một số điều của Pháp lệnh Ngoại hối (viết tắt Nghị định 70) (Chính phủ, 2014). Ngoài ra, Luật Ngân hàng Nhà nước Việt Nam (viết tắt Luật NHNN) được ban hành năm 2010, Luật Các tổ chức tín dụng cũng ban hành năm 2010 và được sửa đổi, bổ sung năm 2017 (viết tắt Luật Các TCTD) (Quốc hội, 2010; 2017) cũng đã có những quy định liên quan đến TTTTPS.

- Nhóm văn bản pháp luật chuyên ngành gồm quy định về phái sinh lãi suất và ngoại hối. Đối với phái sinh lãi suất, Thông tư số 01/2015/ TT-NHNN (Thông tư 01) về quy định hoạt động kinh doanh, cung ứng sản phẩm phái sinh lãi suất của NHTM, CNNHNN. Liên quan đến phái sinh ngoại hối có Thông tư số 15/2015/TTNHNN (viết tắt Thông tư 15) hướng dẫn giao dịch ngoại tệ trên thị trường ngoại tệ của các TCTD (Ngân hàng Nhà nước, 2015) và Thông tư số $21 / 2014 / T T-N H N N$ và được sửa đổi bổ sung bởi Thông tư số 28/2016/TT-NHNN (viết tắt Thông tư 21,28) quy định hoạt động ngoại hối, điều kiện, trình tự, thủ tục chấp thuận hoạt động ngoại hối của TCTD, CNNHNN (Ngân hàng Nhà nước, 2014; 2016).

\section{Kết quả nghiên cứu}

Kết quả khảo sát được tổng hợp từ các chuyên gia là những người am tường và có kinh nghiệm trong thực tế, cụ thể:

\subsection{Về nội dung quy định trong các văn bản pháp luật}

Theo đánh giá chung, hệ thống văn bản pháp luật của phái sinh lãi suất và ngoại hối đã tương đối thống nhất và đầy đủ, cụ thể:
- Khung pháp lý theo thời gian đã có sự chỉnh sửa, bổ sung và ban hành mới một số văn bản pháp luật.

- Các văn bản pháp lý đều đảm bảo tính hệ thống trên cơ sở Luật NHNN, Luật Các TCTD hay Pháp lệnh Ngoại hối, Nghị định 70, Thông tư 01 , Thông tư 15, hay Thông tư 21, 28 sẽ hướng dẫn dựa trên căn cứ trên Luật và Nghị định liên quan.

- Văn bản quy định này đã hoàn thiện về mặt pháp lý cho thị trường tiền tệ đã triển khai các hợp đồng phái sinh về ngoại hối, lãi suất phần lớn đã đáp ứng nhu cầu thực tiễn.

\subsection{Việc áp dụng các văn bản pháp luật trong thục tiễn}

Có thể thấy, hệ thống văn bản pháp luật của phái sinh lãi suất và ngoại hối phần lớn đã đáp ứng nhu cầu thực tiễn nhưng bên cạnh đó vẫn còn một vài bất cập nhất định như:

- Đối với Luật NHNN, điển hình như một giải thích từ ngữ chưa phù hợp với thực tiễn liên quan đến các khoản về phái sinh. Đối với thực hiện chính sách tiền tệ quốc gia chưa quy định rõ trong các hợp đồng chứng khoán phái sinh liên quan đến ngoại hối phái sinh. Các hoạt động thanh toán cũng chưa quy định trong bù trừ phù hợp với các giao dịch phái sinh. Quản lý ngoại hối và hoạt động ngoại hối chưa phù hợp với các hoạt động liên quan đến phái sinh ngoại hối gần đây.

- Đối với Luật Các TCTD, cơ bản thể hiện ở vấn đề giải thích từ ngữ chưa đầy đủ và nhất quán đối với các sản phẩm phái sinh. Đối với phạm vi hoạt động được phép của TCTD chưa quy định về các tổ chức này được tham gia các hoạt động giao dịch, thanh toán bù trừ, kinh doanh, cung ứng dịch vụ ngoại hối và sản phẩm phái sinh.

- Đối với Pháp lệnh Ngoại hối, tập trung ở vấn đề hiện nay chưa có quy định về người cư 
trú là tổ chức phát hành chứng khoán bên ngoài lãnh thổ Việt Nam và người không cư trú là tổ chức phát hành chứng khoán trên lãnh thổ Việt Nam được giao dịch các hoạt động phái sinh ngoại hối. Đối với thị trường ngoại tệ của Việt Nam và thành phần dự trữ ngoại hối nhà nước chưa quy định đối với các hợp đồng phái sinh ngoại hối.

- Đối với Nghị định 70, một số nội dung hướng dẫn chưa phù hợp với thực tiễn trong hoạt động ngoại hối. Hơn nữa, một số vấn đề chưa nhất quán với Pháp lệnh Ngoại hối trong việc giải thích từ ngữ, và tính thống nhất liên quan đến sản phẩm phái sinh và hoạt động ngoại hối.

- Riêng đối với phái sinh lãi suất, văn bản pháp lý đã được ban hành theo Thông tư 01 còn tồn tại ở một số thuật ngữ liên quan đến sản phẩm phái sinh chưa nhất quán với Luật Các TCTD. Hiện tại, hướng dẫn của Thông tư chưa quy định về lãi suất tham chiếu bằng VNĐ để làm cơ sở thực thi các hợp đồng phái sinh cũng như những trường hợp TCTD, CNNHNN được mua, bán ngoại tệ để thanh toán trong các giao dịch từ các hợp đồng phái sinh lãi suất hay ngoại hối.

- Đối với phái sinh ngoại hối, văn bản pháp lý liên quan Thông tư 15, Thông tư 21, 28 một số nội dung chưa nhất quán trong quy định của Luật NHNN, Luật Các TCTD, Pháp lệnh Ngoại hối, Nghị định 70 về thuật ngữ liên quan phái sinh lãi suất. Ngoài ra, hoạt động thanh toán, về quản lý ngoại hối và hoạt động ngoại hối cũng như kinh doanh, cung ứng dịch vụ ngoại hối và sản phẩm phái sinh chưa hướng dẫn thống nhất trong hệ thống văn bản pháp lý.

\section{Kiến nghị hoàn thiện khung pháp lý về thị trường phái sinh tiền tệ tại các ngân hàng thương mại Việt Nam}

Trên cơ sở khảo sát thực trạng áp dụng khung pháp lý TTTTPS Việt Nam, bài viết đề xuất một số kiến nghị cơ bản nhằm hoàn thiện khung pháp lý TTTTPS cho Việt Nam đáp ứng xu thế hội nhập, cụ thể:

- Quốc hội cần khẩn trương hoàn thiện khung pháp lý theo thông lệ quốc tế. Theo đó, đối với Luật NHNN cần cập nhật để phù hợp với tình hình thực tiễn như giải thích từ ngữ cần bổ sung thuật ngữ liên quan phái sinh ngoại hối, lãi suất; cũng như chỉnh sửa, bổ sung thuật ngữ hệ thống thanh toán theo hướng mở rộng liên quan đến các tổ chức thanh toán do NHNN tổ chức, quản lý, vận hành. Đối với Luật Các TCTD, một số quy định cần cập nhật liên quan phạm vi hoạt động được phép của TCTD tham gia các hoạt động trên thị trường phái sinh trong giao dịch, thanh toán, bù trừ. Đối với Pháp lệnh Ngoại hối, cần bổ sung quy định liên quan đến CCPS vì hiện tại chỉ quy định ngoại hối là các loại giấy tờ có giá bằng ngoại tệ, gồm trái phiếu Chính phủ, trái phiếu công ty, kỳ phiếu, cổ phiếu và các loại giấy tờ có giá khác. Ngoài ra, quy định thành phần dự trữ ngoại hối nhà nước cần bổ sung bao gồm cả các chứng khoán phái sinh liên quan đến các hợp đồng ngoại hối phái sinh.

- Chính phủ cần có kế hoạch nghiên cứu để rà soát Nghị định 70 . Theo đó, Nghị định này xem xét chỉnh sửa, bổ sung một số quy định trên cơ sở nhất quán với Pháp lệnh Ngoại hối (đã đề xuất trên) trong đó cần hướng dẫn quy định bổ sung TCTD, CNNHNN được mua, bán ngoại tệ để thanh toán trong các giao dịch từ các hợp đồng phái sinh lãi suất hay ngoại hối. Điều này góp phần đáp ứng nhu cầu thực tiễn của các TCTS, NHTM.

- Ngân hàng Nhà nước, cần rà soát nội dung của Thông tư liên quan đến phái sinh lãi suất và ngoại hối trên cơ sở để đảm bảo tính thống nhất từ thuật ngữ đến nội dung. Theo đó, Thông tư cần quy định rõ lãi suất tham chiếu để làm cơ sở thực thi các hợp đồng phái sinh cũng như hướng dẫn cần bổ sung thành phần dự trữ ngoại hối nhà nước bao gồm cả hợp đồng chứng 
khoán phái sinh liên quan đến ngoại hối. Ngoài ra, đối với hướng dẫn hạch toán kế toán, NHNN cần xem xét ban hành Thông tư hướng dẫn hạch toán kế toán về CCPS liên quan ngoại hối, lãi suất để đảm bảo sự thống nhất trong ghi nhận, đánh giá, trình bày và công bố thông tin trên báo cáo tài chính để đảm bảo tính nhất quán.

\section{Kết luận}

Trong xu hướng toàn cầu hóa, các quốc gia đều tận dụng cơ hội để thu hút nguồn lực tài chính cho phát triển kinh tế thông qua thị trường tài chính nói chung và TTTTPS nói riêng. Việt Nam, quốc gia đang phát triển, đang cần nguồn lực vốn cho tăng trưởng kinh tế nên việc hoàn thiện khung pháp lý cho TTTTPS Việt Nam đáp ứng xu hướng hội nhập quốc tế là vấn đề mang tính thiết yếu. Có thể nhận thấy bên cạnh những thành quả đáng ghi nhận về mức độ thống nhất trong hệ thống các văn bản pháp lý cũng như đã giải quyết phần lớn những vấn đề phát sinh trong thực tiễn liên quan của TTTTPS, tuy nhiên vẫn còn một vài tồn tại nhất định về tính tương thích với thông lệ quốc tế, sự nhất quán trong hệ thống các văn bản quy định, sự chậm cải tiến nên cần phải hoàn thiện hơn nữa để đáp ứng nhu cầu thực tiễn ngày càng cao. Trên cơ sở đó, để góp phần hoàn thiện khung pháp lý TTTTPS Việt Nam, các cơ quan nhà nước cần khẩn trương sửa đổi, bổ sung các Luật, Pháp lệnh, Nghị định và Thông tư liên quan nhằm tạo sự thống nhất trong hệ thống pháp lý trên cơ sở cần phù hợp với thông lệ quốc tế, đảm bảo tính thống nhất và kịp thời, hoàn thiện thanh toán giao dịch, bù trừ, vấn đề về quy định kế toán liên quan đến CCPS về lãi suất và ngoại hối. Điều này sẽ giúp lành mạnh hóa môi trường pháp lý cho TTTTPS Việt Nam phát triển đáp ứng xu thế hội nhập quốc tế.

\section{Tài liệu tham khảo}

\section{Tiếng Việt}

Bộ Tài chính (2014). Thông tư số 21/2014/TT-NHNN hướng dẫn về phạm vi hoạt động ngoại hối, điều kiện, trình tự, thủ tục chấp thuận hoạt động ngoại hối của tổ chức tín dụng, chi nhánh ngân hàng nước ngoài

Bộ Tài chính (2015a). Thông tư số 01/2015/TT-NHNN qui định hoạt động kinh doanh, cung ứng sản phẩm phái sinh lãi suất của NHTM, CNNHNN

Bộ Tài chính (2015b). Thông tư số 15/2015/TT-NHNN hướng dẫn giao dịch ngoại tệ trên thị trường ngoại tệ của TCTD được phép hoạt động ngoại hối

Bộ Tài chính (2016). Thông tư số 28/2016/TT-NHNN sửa đổi, bổ sung một số điều của Thông tư số 21/2014/TT-NHNN hướng dẫn về phạm vi hoạt động ngoại hối, điều kiện, trình tự, thủ tục chấp thuận hoạt động ngoại hối của tổ chức tín dụng, chi nhánh ngân hàng nước ngoài

Chính phủ (2014). Quyết định số 70/2014/NĐ-CP qui định chi tiết thi hành một số điều của Pháp lệnh Ngoại hối và Pháp lệnh sửa đổi, bổ sung một số điều của Pháp lệnh Ngoại hối.

Chính phủ (2018). Quyết định số 986/QĐ-TTg về chiến lược phát triển ngành Ngân hàng Việt Nam đến năm 2025, định hướng đến năm 2030

NHNN (2006). Công văn số 7404/NHNN-KTTC về hướng dẫn hạch toán kế toán nghiệp vụ phái sinh tiền tệ

Nguyễn Thị Loan (2013). Phát triển CCTCPS tiền tệ tại các NHTM Việt Nam. Tạp chí Khoa học và Đào tạo Ngân hàng, Tháng 10/2013 
Nguyễn Thị Nhung và Trần Thị Minh Tuyền (2014). Úng dụng các công cụ phái sinh trong quản trị rủi ro lãi suất tại các NHTM. Tạp chí Phát triển và Hội nhập, Số 15 (25), trang 41-45

Nguyễn Thị Lan (2017). Vai trò điều tiết thị trường ngoại tệ của Ngân hàng Nhà nước Việt Nam hiện nay. Tạp chí Cộng Sản, Tháng 10/2017

Nguyễn Thúy (2008). Phát triển các công cụ phái sinh trên thị trường ngoại hối Việt Nam. Tạp chí Công nghệ Ngân hàng, số 31, trang 16-18

Quốc hội (2010a). Số 46/2010/QH12 về Luật Ngân hàng Nhà nước Việt Nam

Quốc hội (2010b). Số 47/2010/QH12 về Luật Các TCTD

Quốc hội (2017). Số 17/2017/QH14 về Luật sửa đổi, bổ sung một số điều của Luật Các TCTD

Trần Thị Khám Trâm, Nguyễn Hồ Thị Phương Thảo và Vũ Thị Kim Nhung (2018). Phát triển sản phẩm phái sinh ngoại hối: Nghiên cứu thực trạng ở thành phố Huế. Tạp chí Tài chính, Tháng $12 / 2018$

UBTVQH (2005). Số 28/2005/PL-UBTVQH11 về Pháp lệnh Ngoại hối

UBTVQH (2013). Số 06/2013/PL-UBTVQH13 về Pháp lệnh sửa đổi, bổ sung một số điều của Pháp lệnh Ngoại hối

\section{Tiếng Anh}

AEMC (2017). Electricity Network Economic Regulatory Framework Review. Australian Emergy Market Commission, July 2017, pp 1-88

Amato, J. D. and Gyntelberg, J. (2005). CDS index tranches and the pricing of credit risk Correlations. BIS Quarterly Review, March 2005, pp 73-87

BIS (2019). Exchange-traded futures and options, by location of exchange. [on line] Available at: $<$ https://stats.bis.org/statx/srs/table/d1.>. [Accessed March 11, 2019].

Biggins, J. and Scott, C. (2013). Private Governance, Public Implications and the Tightrope of Regulatory Reform: The ISDA Credit Derivatives Determinations Committees. Comparative Research in Law \& Political Economy. Research Paper No. 57/2013, pp299-304

Carlson, J. B., Craig, B., Higgins, P., Melick, W. R. (2006). FOMC Communications and the Predictability of Near-Term Policy Decisions. Federal Reserve Bank of Cleveland, June 2006

Chance, D. M and Brooks, R. (2016). Introduction to Derivatives and Risk Management. Cengage Learning US, 10th Edition, pp1-640

Chiu, M. (2010). Derivatives markets, products and participants: an overview. IFC Bulletin No 35, pp 3-11

IFRS Foundation (2019). IFRS Standards and IFRIC Interpretations. [on line] Available at: $<$ https:// www.ifrs.org/issued-standards.>. [Accessed January 10, 2019].

IOSCO (2018). Annual Report, IOCU-IOSCO, December 2017, pp 1-88

Tiwari, S. and Turan, M. S. (2004). Introduction To Derivative Securities. [on line] Available at: $<$ www.ddegjust.ac.in/studymaterial/mba/fm-407>. [Accessed January 2, 2019].

Vashishtha, A. and Kumar, S. (2010). Development of Financial Derivatives Market in India- A Case Study. International Research Journal of Finance and Economics, Issue 37 (2010), pp 16-29

Weber, E. J. (2009). A Short History of Derivative Security Markets. In Vinzenz Bronzin's option pricing models: Exposition and appraisal, pp 431-440, Springer Science \& Business Media. 